\title{
Treatment of Unruptured Distal Anterior Circulation Aneurysms with Flow-Diverter Stents: A Meta-Analysis
}

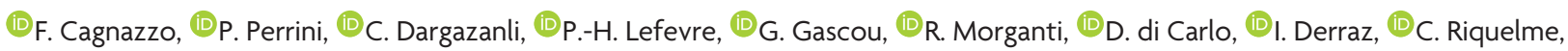 \\ (1)A. Bonafe, and 낙. Costalat
}

\begin{abstract}
BACKGROUND: The safety and efficacy of flow diversion among distal anterior circulation aneurysms must be proved.

PURPOSE: Our aim was to analyze the outcomes after flow diversion among MCA, anterior communicating artery, and distal anterior cerebral artery aneurysms.
\end{abstract}

DATA SOURCES: A systematic search of 3 databases was performed for studies published from 2005 to 2018.

STUDY SELECTION: According to Preferred Reporting Items for Systematic Reviews and Meta-Analyses guidelines, we included studies reporting flow diversion of distal anterior circulation aneurysms.

DATA ANALYSIS: Random-effects meta-analysis was used to pool aneurysm occlusion and complication rates. From the individual patient data, univariate and multivariate analyses were used to test predictors of occlusion and complications.

DATA SYNTHESIS: We included 27 studies (484 aneurysms). The long-term adequate occlusion rate (O'Kelly-Marotta scale, C-D) was 82.7\% (295/364; 95\% Cl, 77.4\%-87.9\%; $\left.I^{2}=52 \%\right)$. Treatment-related complications were $12.5 \%\left(63 / 410 ; 95 \% \mathrm{Cl}, 9 \%-16 \% \%\right.$; $\left.I^{2}=18.8 \%\right)$, with $5.4 \%\left(29 / 418 ; 95 \% \mathrm{Cl}, 3.2 \%-7.5 \% ; I^{2}=0 \%\right)$ morbidity. MCA location was an independent factor associated with lower occlusion (OR $=0.5$, $P=.03$ ) and higher complication rates (OR $=1.8, P=.02$ ), compared with anterior communicating artery and distal anterior cerebral artery aneurysms. The Pipeline Embolization Device (versus other stents) gave better occlusion rates (OR $=2.6, P=.002)$, whereas large/giant aneurysms were associated with higher odds of complications (OR $=2.2, P=.03)$. The rates of occlusion and narrowing of arteries covered by flow-diverter stents were $6.3 \%\left(29 / 283 ; 95 \% \mathrm{Cl}, 3.5 \%-9.1 \%\right.$; $\left.I^{2}=4.2 \%\right)$ and $23.8 \%\left(69 / 283 ; 95 \% \mathrm{Cl}, 15.7 \%-32 \%\right.$; $\left.I^{2}=80 \%\right)$, respectively. Symptoms related to occlusion and narrowing of the jailed arteries were $3.5 \%\left(6 / 269 ; 95 \% \mathrm{Cl}, 1.1 \%-5 \% ; \mathrm{I}^{2}=0 \%\right)$ and $3 \%(6 / 245 ; 95 \% \mathrm{Cl}$, $\left.1 \%-4 \% ; I^{2}=0 \%\right)$, respectively.

LIMITATIONS: We reviewed small and retrospective series.

CONCLUSIONS: Flow diversion among distal anterior circulation aneurysms is effective, leading to adequate aneurysm occlusion in $83 \%$ of cases. However, this strategy has some limitations among MCA and larger lesions, especially related to the higher rate of complications. Compared with the other devices, the Pipeline Embolization Device seems to be associated with a higher occlusion rate.

ABBREVIATIONS: $\mathrm{AC}=$ anterior circulation; $\mathrm{AcomA}=$ anterior communicating artery; $\mathrm{AT}=$ antiplatelet therapy; $\mathrm{DACA}=$ distal anterior cerebral artery; $\mathrm{FD}=$ flow diversion

$\mathrm{T}$ he off-label uses of flow diversion (FD) for the treatment of intracranial aneurysms have increased, including distal locations and bifurcation aneurysms. ${ }^{1}$ The smaller diameters of the

Received December 5, 2018; accepted after revision January 28, 2019.

From the Neuroradiology Department (F.C., C.D., P.-H.L., G.G., I.D., C.R., A.B., V.C.), University Hospital Güi-de-Chauliac, Centre Hospitalier Universitaire de Montpellier, Montpellier, France; and Department of Neurosurgery (P.P., D.d.C.) and Section of Statistics (R.M.), University of Pisa, Pisa, Italy.

Please address correspondence to Federico Cagnazzo, MD, Neuroradiology Department, CHU Gui De Chauliac, 80 Ave Augustin Fliche, 34000 Montpellier, France; e-mail: f.cagnazzo86@gmail.com arteries, the technical challenges of the distal navigation, and the coverage of bifurcation branches and perforators may increase the risk of treatment-related complications. ${ }^{1-4}$ Few series have investigated the safety and efficacy of these devices among distal anterior circulation (AC) aneurysms. The aim of our meta-analysis was to report the outcome after FD treatment among the 3 most common AC distal locations: the MCA, anterior communicating

Indicates article with supplemental on-line tables.

indicates article with supplemental on-line photos.

http://dx.doi.org/10.3174/ajnr.A6002

AJNR Am J Neuroradiol 40:687-93 Apr 2019 www.ajnr.org 
$\operatorname{artery}($ AcomA), and distal anterior cerebral artery (DACA) (pericallosal) segments.

\section{MATERIALS AND METHODS Literature Search}

A comprehensive literature search of PubMed, Ovid EMBASE, and Scopus was conducted for studies published from January 2005 to November 2018. Preferred Reporting Items for Systematic Reviews and Meta-Analyses guidelines ${ }^{5}$ were followed. The detailed search strategy is reported in On-line Table 1, and the included studies are reported in On-line Table 2. The inclusion criteria were the following: studies reporting series with distally located AC unruptured aneurysms treated with FD. We considered the following distal locations: MCA (early cortical branches and MCA main bifurcation ${ }^{6}$ ), AcomA, and DACA arising at or beyond the A2 segment. Previously ruptured aneurysms showing recanalization after embolization in the acute phase were included if flow diversion was used as a retreatment strategy. Exclusion criteria were the following: 1) case reports, 2) review articles, 3) studies published in languages other than English, 4) in vitro/animal studies, and 5) series reporting an A1 location. In cases of overlapping patient populations, only the series with the largest number of patients or the most detailed data were included. Two independent readers screened articles in their entirety to determine eligibility for inclusion. A third author solved discrepancies.

\section{Data Collection}

We extracted the following: 1) occlusion rate, 2) treatment-related complications, and 3) clinical outcome.

Complete/near-complete aneurysm occlusion was defined on the basis of the following: O' Kelly Marotta grades C-D, ${ }^{7}$ Raymond-Roy classification ${ }^{8}$ (classes I-II), or when "complete occlusion" and "neck remnant" were used in the study. Treatment-related complications were divided into the following: 1) periprocedural (within 30 days) and delayed events (after 30 days); 2) transient (asymptomatic events or complete neurologic recovery) and permanent complications (symptomatic events with permanent deficits); and 3) ischemic and hemorrhagic complications. Small and large aneurysms were considered $<10 \mathrm{~mm}$ and $\geq 10 \mathrm{~mm}$, respectively. Flow diversion and coiling, compared with the group of flow diversion alone, was considered if coiling was performed in the same treatment session as the flow diverter procedure; patients with a previously coiled aneurysm were not counted in this subgroup. The angiographic outcome of covered arteries was evaluated as follows: 1) normal, 2) arterial narrowing, and 3) arterial occlusion. Finally, good outcome was defined as a modified Rankin Scale score of 0-2 or when the study reported "no morbidity," "good recovery," or "no symptoms."

\section{Outcomes}

The primary objectives of this study were to define the safety (treatment-related complications, morbidity rates) and the efficacy (technical success rate, long-term occlusion) of FD for distal $\mathrm{AC}$ aneurysms. The secondary objectives were to define the influence of aneurysm, patient, and treatment characteristics on the analyzed outcomes.

\section{Quality Scoring}

A modified version of the Newcastle-Ottawa Scale ${ }^{9}$ was used for the quality assessment of the included studies (details in On-line Table 3). The quality assessment was performed by 2 authors independently, and a third author solved discrepancies.

\section{Statistical Analysis}

Meta-Analysis. We estimated, from each cohort, the cumulative prevalence and 95\% confidence interval for each outcome. Heterogeneity of the data was assessed by the Higgins Index $\left(\mathrm{I}^{2}\right)$, and subsequently, the DerSimonian and Laird random-effects model were applied. The graphic representation was performed by forest plots. To evaluate the heterogeneity and bias, we analyzed the meta-regression and the funnel plots followed by the Egger linear regression test, respectively. To verify the consistency of the metaanalysis results outcome, we assessed the influence of each individual study by the sensitivity analysis (leave-one-out approach). Differences among subgroups of analyses were considered significant at $P<.05$. Meta-analysis was performed with ProMeta-2 (Internovi, Cesena, Italy) and OpenMeta[Analyst] (https://idostatistics.com/prometa3/).

Univariate and Multivariate Analyses. From the individual patient data, ${ }^{10}$ we extracted the following dependent variables: aneurysm occlusion (complete-versus-incomplete occlusion) and treatment-related complications (complications versus no complications). Individual patient data of dissecting and fusiform aneurysms were reasonably excluded, and the analysis was mostly performed on the saccular type. The $\chi^{2}$ test was used to evaluate qualitative factors associated with occlusion and complications (type of FD, aneurysm location, number of stents, FD alone versus FD and coiling). The independent variables significantly associated (in the univariate analysis) with aneurysm complete occlusion or complications were analyzed together in a binary logistic regression (multivariate analysis) to assess the independent contribution of each factor. The results of the regression model were calculated by the Wald test and expressed using $P$ values and related odds ratio. All statistical analyses were performed with SPSS, Version 24 (IBM, Armonk, New York).

\section{RESULTS}

\section{Literature Review}

Studies included in our meta-analysis are summarized in On-line Table 2. The search flow diagram is shown in On-line Fig 1.

A total of 27 studies and 484 distal AC aneurysms treated with FD were included. Overall, we extracted 286 MCA aneurysms from 16 studies, 145 AcomA aneurysms from 12 studies, and 53 DACA aneurysms from 6 studies.

\section{Quality of Studies}

Overall, 22 included studies were retrospective series, ${ }^{1,2,4,11-28}$ whereas 5 articles were prospective series (details in On-line Table 3). ${ }^{29-33}$

\section{Patient Population and Aneurysm Characteristics}

The mean age of patients was 54.5 years (range, $18-82$ years), and the proportion of male patients was $36 \%$ (95\% CI, 31\%-41\%) 
Table 1: Outcomes after flow diversion treatment of distal anterior circulation intracranial aneurysms

\begin{tabular}{|c|c|c|c|}
\hline Variables & $\begin{array}{c}\text { Results of Systematic } \\
\text { Review and } \\
\text { Meta-Analysis }\end{array}$ & $\begin{array}{c}\text { No. of } \\
\text { Articles }\end{array}$ & $\begin{array}{c}\text { Statistic } \\
(95 \% \mathrm{CI})\left(\mathrm{I}^{2}\right)\end{array}$ \\
\hline \multicolumn{4}{|l|}{ Angiographic outcomes } \\
\hline Rate of successful stent deployment & $422 / 429=97.5 \%$ & 29 & $(96-98.9)\left(I^{2}=0 \%\right)$ \\
\hline Immediate aneurysm occlusion rate (OKM C-D) & $44 / 333=11.1 \%$ & 18 & $(6.5-16)\left(1^{2}=55 \%\right)$ \\
\hline Overall long-term aneurysm occlusion rate (OKM C-D) & $295 / 364=82.7 \%$ & 28 & $(77.4-87.9)\left(1^{2}=52 \%\right)$ \\
\hline Long-term occlusion rate (MCA location) & $163 / 206=78 \%$ & 13 & $(69-88)\left(1^{2}=73.7 \%\right)$ \\
\hline Long-term occlusion rate (AcomA location) & $91 / 105=88 \%$ & 13 & $(82-94)\left(I^{2}=0 \%\right)$ \\
\hline Long-term occlusion rate (DACA location) & $41 / 53=82 \%$ & 6 & $(70.7-90.7)\left(1^{2}=0 \%\right)$ \\
\hline Long-term occlusion rate (FRED device) & $37 / 53=73.8 \%$ & 7 & $(60.1-87.5)\left(1^{2}=31.7\right)$ \\
\hline Long-term occlusion rate (p64 device) & $18 / 22=82 \%$ & 2 & $(64-98)\left(I^{2}=41.7 \%\right)$ \\
\hline Long-term occlusion rate (PED device) & $143 / 165=87.3 \%$ & 13 & $(82.4-92.3)\left(1^{2}=0 \%\right)$ \\
\hline Long-term occlusion rate (Surpass device) & $11 / 14=80.9 \%$ & 2 & $(55.5-98)\left(1^{2}=29.3 \%\right)$ \\
\hline \multicolumn{4}{|l|}{ Treatment-related complications and clinical outcomes } \\
\hline Overall treatment-related complications & $63 / 410=12.5 \%$ & 28 & $(9-16)\left(1^{2}==18.8 \%\right)$ \\
\hline Treatment-related complications (MCA location) & $44 / 231=18 \%$ & 12 & $(12-25)\left(1^{2}=42 \%\right)$ \\
\hline Treatment-related complications (AcomA location) & $14 / 126=8 \%$ & 10 & $(3-13)\left(I^{2}=0 \%\right)$ \\
\hline Treatment-related complications (DACA location) & $5 / 53=9 \%$ & 6 & $(5-17)\left(1^{2}=0 \%\right)$ \\
\hline Periprocedural/early complications (within 30 days) & $30 / 418=5.9 \%$ & 28 & $(3.7-8)\left(1^{2}=0 \%\right)$ \\
\hline Delayed complications (after 30 days) & $35 / 418=6.5 \%$ & 28 & $(3.4-8.4)\left(1^{2}=20 \%\right)$ \\
\hline Transient complications & $37 / 418=6.7 \%$ & 28 & $(4.4-9)\left(1^{2}=0 \%\right)$ \\
\hline Permanent complications & $29 / 418=5.4 \%$ & 28 & $(3.3-7.5)\left(1^{2}=0 \%\right)$ \\
\hline Treatment-related complications (FRED device) & $9 / 66=11.7 \%$ & 28 & $(3.2-20.3)\left(1^{2}=29 \%\right)$ \\
\hline Treatment-related complications (p64 device) & $3 / 23=12.5 \%$ & 2 & $(1-26)\left(1^{2}=0 \%\right)$ \\
\hline Treatment-related complications (PED device) & $20 / 159=9.2 \%$ & 12 & $(4.9-13.5)\left(1^{2}=0 \%\right)$ \\
\hline Treatment-related complications (Silk device) & $2 / 20=8.2 \%$ & 3 & $(3.2-19.5)\left(1^{2}=0 \%\right)$ \\
\hline Treatment-related mortality & $5 / 374=2.2 \%$ & 23 & $(0.8-3.7)\left(1^{2}=0 \%\right)$ \\
\hline Overall rate of good neurologic outcome & $290 / 304=97 \%$ & 23 & $(96-99)\left(1^{2}=0 \%\right)$ \\
\hline \multicolumn{4}{|l|}{ Type of complications and location } \\
\hline Thromboembolic complications & $54 / 418=9.9 \%$ & 29 & $(7-12.7)\left(1^{2}=6.6 \%\right)$ \\
\hline Thromboembolic complications (MCA location) & $40 / 239=14.6 \%$ & 12 & $(9-20)\left(1^{2}=33 \%\right)$ \\
\hline Thromboembolic complications (AcomA location) & $10 / 126=6 \%$ & 10 & $(2-10)\left(1^{2}=0 \%\right)$ \\
\hline Thromboembolic complications (DACA location) & $4 / 53=7 \%$ & 6 & $(1.5-16)\left(1^{2}=0 \%\right)$ \\
\hline Hemorrhagic complications & $7 / 418=2.6 \%$ & 29 & $(1.1-4)\left(1^{2}=0 \%\right)$ \\
\hline Premature discontinuation of AT and related ischemic events & $6 / 418=2.8 \%$ & 29 & $(1.3-4.3)\left(1^{2}=0 \%\right)$ \\
\hline
\end{tabular}

Note:-OKM indicates O’Kelly-Marotta scale.

(On-line Table 4). Aneurysms included in our study were unruptured lesions with a mean size of $6 \mathrm{~mm}$ (median, $5.7 \mathrm{~mm}$; range, 2-21 mm). The most common device was the Pipeline Embolization Device (PED; Covidien, Irvine, California) (62\%; 95\% CI, 57\%-66\%), followed by the Flow-Redirection Endoluminal Device (FRED; MicroVention, Tustin, California) (15.5\%; 95\% CI, 12\%-19\%), the Silk flow diverter (Balt Extrusion, Montmorency, France) $(10.5 \%$; 95\% CI, 8\%-13\%), the p64 (phenox, Bochum, Germany ) (7\%; 95\% CI, 4\%-9\%), and the Surpass stent (Stryker Neurovascular, Kalamazoo, Michigan) (5\%; 95\% CI, 3\%-7\%).

The mean radiologic (digital subtraction angiography) follow-up was 12 months (range, 4-28 months; median, 12.5 months; interquartile range $=10-12.5$ months), and the mean clinical follow-up was 13 months (range, 6-30 months; median, 12 months; interquartile range $=10-14$ months).

\section{Angiographic Outcomes}

Given the interstudy differences in terms of patient population, aneurysm features, aneurysm locations, and type of device used, random-effects meta-analysis was adopted to report the studied outcomes because this model incorporates heterogeneity among studies. The technical success rate was 97.5\% (422/429; 95\% CI, 96\%-98.9\%; $\mathrm{I}^{2}=0 \%$ ) (Table 1). Immediate angiographic occlusion (O'Kelly-Marotta scale, C-D) after treatment was obtained in $11.1 \%\left(44 / 333 ; 95 \%\right.$ CI, $\left.6.5 \%-16 \% ; \mathrm{I}^{2}=55 \%\right)$ of aneurysms. The rate of long-term complete/near-complete occlusion was $82.7 \%$ (295/364; 95\% CI, 77.4\%-87.9\%; I² = 52\%). Meta-regression showed a nonsignificant variation of the effect size $(P=.91)$ during the analyzed period, and the funnel plot (Egger linear regression test) excludes publication bias $(P=.09)$. The sensitivity analysis showed that no individual study significantly influenced the combined aneurysm occlusion rate, indicating the robust results of this meta-analysis (On-line Fig 2).

\section{Treatment-Related Complications}

The overall complication rate was 12.5\% (63/410; 95\% CI, 9\%$16 \% \% ; \mathrm{I}^{2}=18.8 \%$ ) (Table 1). Meta-regression showed a trend toward lower rates of complications during the analyzed period $(P=.058)$. The funnel plot excludes publication bias $(P=.33)$. In addition, no individual study significantly influenced the treatment-related complication rate (On-line Fig 3). Periprocedural/ early complications were 5.9\% (30/418; 95\% CI, 3.7\%-8\%; $\mathrm{I}^{2}=$ $0 \%$ ). Delayed complications were $6.5 \%$ (35/418; 95\% CI, 3.4\%$\left.8.4 \% ; \mathrm{I}^{2}=0 \%\right)$. Transient and permanent complications were 6.7\% (33/418; 95\% CI, 4.4\%-9\%; $\left.\mathrm{I}^{2}=0 \%\right)$ and 5.4\% (29/418; $95 \%$ CI, 3.3\%-7.5\%; $\mathrm{I}^{2}=0 \%$ ), respectively.

Overall, ischemic/thromboembolic and hemorrhagic events were $9.9 \%\left(54 / 418 ; 95 \% \mathrm{CI}, 7 \%-12.7 \% ; \mathrm{I}^{2}=6.6 \%\right)$ and $2.6 \%$ 
Table 2: Univariate and multivariate analysis of predicting factors for aneurysm occlusion and treatment-related complications

\begin{tabular}{|c|c|c|c|c|c|}
\hline & \multirow{2}{*}{$\begin{array}{c}\text { Univariate, } \\
P \text { Value }\end{array}$} & \multirow{2}{*}{$\begin{array}{c}\text { Univariate } \\
\text { OR }\end{array}$} & \multicolumn{3}{|c|}{ Multivariate } \\
\hline & & & Odds Ratio & $95 \% \mathrm{Cl}$ & $P$ Value \\
\hline \multicolumn{6}{|l|}{ Independent variables for occlusion } \\
\hline Type of FD (PED vs other) & .002 & 1.4 & 2.6 & $1.6-5.3$ & $.02^{\mathrm{a}}$ \\
\hline No. of FDs (multiple vs single) & .07 & 1.3 & 2.3 & $0.8-7.2$ & .08 \\
\hline Aneurysm size (large vs small) ${ }^{b}$ & .3 & 1.1 & & & \\
\hline FD + coils vs FD alone & .006 & 1.9 & 1.8 & $0.8-3.4$ & .11 \\
\hline Aneurysm location (MCA vs AcomA/DACA) & .01 & 0.9 & 0.5 & $0.2-0.7$ & $.03^{\mathrm{a}}$ \\
\hline \multicolumn{6}{|l|}{ Independent variables for complications } \\
\hline Type of FD (PED vs other) & .5 & 1.3 & & & \\
\hline No. of FDs (multiple vs single) & .4 & 1.5 & & & \\
\hline Aneurysm size (large vs small) ${ }^{\mathrm{b}}$ & .06 & 2.4 & 2.2 & $1-8.3$ & $.03^{\mathrm{a}}$ \\
\hline FD + coils vs FD alone & .5 & 0.9 & & & \\
\hline Aneurysm location (MCA vs AcomA/DACA) & .01 & 2.9 & 1.8 & $1.1-7.6$ & $.02^{\mathrm{a}}$ \\
\hline
\end{tabular}

(7/418; 95\% CI, 1.1\%-4\%; I $\left.{ }^{2}=0 \%\right)$, respectively. Ischemic events were higher in the MCA location $(40 / 239=14.6 \%$; $95 \%$ CI, 9\%-20\%; $\left.\mathrm{I}^{2}=33 \%\right)$ compared with the AcomA $(10 / 126=$ $6 \% ; 95 \%$ CI, $\left.2 \%-10 \% ; I^{2}=0 \%\right)$ and DACA locations $(4 / 53=$ $7 \%$; $95 \% \mathrm{CI}, 1.5 \%-16 \%$; $\left.\mathrm{I}^{2}=0 \%\right)$. The rate of ischemic complications related to the premature discontinuation of the antiplatelet therapy (AT) (which means that the patient discontinued the AT before the required period) was 2.8\% (6/418; 95\% CI, 1.3\%$\left.4.3 \% ; \mathrm{I}^{2}=0 \%\right)$. There was only 1 case of rupture after treatment during 2 years of follow-up: it was a previously ruptured MCA aneurysm treated with coils and multiple FDs. ${ }^{26}$

Treatment-related mortality was 2.2\% (5/374; 95\% CI, 0.8\%$\left.3.7 \% ; \mathrm{I}^{2}=0 \%\right)$, and the rate of good neurologic outcome was 97\% (290/304; 95\% CI, 96\%-99\%; I² = 0\%).

\section{Subgroups Analysis: Factors Related to Aneurysm Occlusion}

The long-term complete/near-complete occlusion rate was higher among AcomA (91/105 = 88\%; 95\% CI, 82\%-94\%; $\left.\mathrm{I}^{2}=0 \%\right)$ and DACA $(41 / 53=82 \% ; 95 \%$ CI, 70.7\%-90.7\%; $\left.\mathrm{I}^{2}=0 \%\right)$ compared with the MCA location $(163 / 206=78 \%$; 95\% CI, 69\%-88\%; $\left.\mathrm{I}^{2}=73.7 \%\right)$. Treatment with the PED was associated with a higher occlusion rate $(143 / 165=87.3 \%$; $95 \%$ CI, 82.4\%-92.3\%; $\mathrm{I}^{2}=0 \%$ ) compared with the other devices (FRED, Surpass, p64) (Table 1). Overall, occlusion rates were comparable among aneurysms treated with FD alone versus FD and coils, single FD versus multiple FDs, and small $(<10$ $\mathrm{mm})$ versus large $(\geq 10 \mathrm{~mm})$ aneurysms $(P>.05)$. In addition, the occlusion rate was comparable among fusiform/dissecting and saccular aneurysms (On-line Table 5). The mean aneurysm size of lesions completely and incompletely occluded was $6 \pm 4.6$ and $6.5 \pm 6.3 \mathrm{~mm}(P=.3)$. There was a trend toward a lower mean age in patients with complete aneurysm occlusion (54 versus 60 years, $P=.06$ ).

Overall, individual patient data were available for $80 \%$ of patients (Table 2). The multivariate analysis showed that PED devices (versus other stents) were associated with higher occlusion $(\mathrm{OR}=2.6, P=.02)$, whereas the MCA location (versus AcomA/DACA) was associated with lower occlusion $(\mathrm{OR}=$ $0.5, P=.03)$.

\section{Subgroup Analysis: Factors Related to Complications}

The complication rate was higher for MCA aneurysms (44/231= 18\%; 95\% CI, 12\%-25\%; $\mathrm{I}^{2}=42 \%$ ) compared with AcomA (14/ $126=8 \% ; 95 \%$ CI, 3\%-13\%; $\left.\mathrm{I}^{2}=0 \%\right)$ and DACA aneurysms $\left(5 / 53=9 \% ; 95 \%\right.$ CI, 5\%-17\%; $\left.\mathrm{I}^{2}=0 \%\right)$. Complication rates after the PED $\left(20 / 159=9.2 \%\right.$; $95 \%$ CI, $\left.4.9 \%-13.5 \% ; \mathrm{I}^{2}=0 \%\right)$ and Silk devices $\left(2 / 20=8.2 \%\right.$; 95\% CI, 3.2\%-19.5\%; $\left.\mathrm{I}^{2}=0 \%\right)$ were slightly lower compared with the FRED $(9 / 66=11.7 \%$; $95 \%$ CI, 3.2\%-20.3\%; $\left.\mathrm{I}^{2}=29 \%\right)$ and p64 devices $(3 / 23=12.5 \%$; $95 \%$ CI, $1 \%-26 \%$; $\left.\mathrm{I}^{2}=0 \%\right)$. Overall, treatment-related complication rates were not significantly associated with the number of stents, treatment with or without coils, age, and type of aneurysm (fusiform/ dissecting versus saccular $)(P>.05)$. There was a trend toward higher mean aneurysm size in patients presenting with complications $(7 \pm$ 4.3 versus $4.4 \pm 4.5 \mathrm{~mm})(P=.06)$. The adverse event rate was lower among small aneurysms $(<10 \mathrm{~mm})$ versus large lesions $(\geq 10 \mathrm{~mm})$ $(\mathrm{OR}=0.4, P=.04)($ On-line Table 5).

The multivariate analysis confirmed larger size aneurysms $(\geq 10 \mathrm{~mm})(\mathrm{OR}=2.2, P=.03)$ and MCA location $(\mathrm{OR}=1.8, P=$ $.02)$ as factors independently associated with higher rates of complications (Table 2).

\section{Outcome of Covered Arteries}

Overall, the rates of occlusion and narrowing of arterial branches covered by FD were 6.3\% $\left(29 / 283 ; 95 \%\right.$ CI, 3.5\%-9.1\%; $\mathrm{I}^{2}=$ $4.2 \%)$ and $23.8 \%\left(69 / 283\right.$; 95\% CI, $15.7 \%-32 \%$; $\left.\mathrm{I}^{2}=80 \%\right)$, respectively (On-line Table 6 and On-line Fig 4). Symptoms related to occlusion and narrowing/slow flow of covered branches were $3.5 \%\left(6 / 269 ; 95 \%\right.$ CI, $\left.1.1 \%-5 \% ; \mathrm{I}^{2}=0 \%\right)$ and $3 \%(6 / 245 ; 95 \%$ CI, $1 \%-4 \% ; \mathrm{I}^{2}=0 \%$ ), respectively. The rate of occlusion of covered vessels in the MCA location (M2 or early cortical branches) was 7.3\% (22/207; 95\% CI, 3.5\%-11\%; $\left.\mathrm{I}^{2}=15 \%\right)$, whereas in the anterior cerebral artery location (A2, callosomarginal artery, artery of Heubner), it was $5.5 \%\left(7 / 76 ; 95 \% \mathrm{CI}, 1 \%-11 \%\right.$; $\left.\mathrm{I}^{2}=0 \%\right)$, respectively. The rates of occlusion of jailed arteries were $7.7 \%(11 / 124 ; 95 \% \mathrm{CI}$, $\left.3.2 \%-12 \% ; \mathrm{I}^{2}=0 \%\right)$ and $7 \%\left(9 / 61 ; 95 \% \mathrm{CI}, 3.5 \%-10 \% ; \mathrm{I}^{2}=0 \%\right)$ among the PED group and other devices, respectively.

\section{Study Heterogeneity}

Heterogeneity was low $(<50 \%)$ for all the reported outcomes except for the following: immediate aneurysm occlusion, long- 
term occlusion among MCA aneurysms, and rate of narrowing of covered vessels.

\section{DISCUSSION}

Our meta-analysis of approximately 500 AC distal aneurysms showed that FD treatment was effective, with a rate of technical success and long-term adequate aneurysm occlusion (O'KellyMarotta scale, C-D) close to $97 \%$ and $83 \%$, respectively. Most interesting, the subgroup analysis showed better angiographic occlusion among AcomA and DACA aneurysms (88\% and 82\%; O'Kelly-Marotta scale, C-D) compared with MCA location (78\%). The binary logistic regression revealed MCA location and treatment with the PED as independent factors associated with lower $(\mathrm{OR}=0.5, P=.03)$ and higher occlusion rates $(\mathrm{OR}=2.6$, $P=.02$ ), respectively. Although FD treatment was relatively safe with overall rates of complications and morbidity of $12 \%$ and $5 \%$, respectively, the MCA location was associated with higher adverse events (18\%). Accordingly, in the multivariate analysis, MCA aneurysms $(\mathrm{OR}=1.8, P=.02)$ and the aneurysm size (large aneurysms $[\geq 10 \mathrm{~mm}]$ versus small aneurysms $[<10 \mathrm{~mm}])(\mathrm{OR}=2.2$, $P=.03$ ) were independent factors associated with adverse events. These results can guide the practitioners during the off-label use of FD stents for the treatment of distal AC aneurysms.

\section{Angiographic Outcome}

Overall, large prospective studies and meta-analyses reported a complete occlusion rate after FD close to $75 \% .^{34,35}$ Our study demonstrated comparable results among distal AC aneurysms, with an $82 \%$ complete/near-complete occlusion rate. The MCA location was an independent factor of incomplete occlusion $(\mathrm{OR}=0.5, P=.03)$. A previous meta-analysis focusing on the endovascular treatment of MCA aneurysms before the era of FD revealed approximately $83 \%$ adequate occlusion. ${ }^{36}$ On the contrary, a very recent review comparing coiling versus clipping of unruptured MCA aneurysms reported 53\% and 95\% long-term complete occlusion, respectively. ${ }^{37}$ These data highlighted heterogeneous rates of adequate occlusion among endovascular series of MCA aneurysms. These outcomes are likely related to different factors: 1) the anatomic variations (sometime with an unfavorable configuration); 2) the presence of wide-neck and branching vessels arising from the aneurysm; and 3 ) the more difficult angiographic visualization of the aneurysm neck and sac. In addition, most of the MCA aneurysms arose from the main bifurcation point, whereas approximately $20 \%$ of lesions originated from an early cortical branch (temporal or frontal). ${ }^{6}$ Very few studies reported a distinction between early cortical branch aneurysms (that have a close relation with perforators) and bifurcation aneurysms (that are close to or incorporate M2 branches); this can influence the outcomes after the endovascular treatments. ${ }^{3}$ All of the above reported features can partially explain the higher rate of heterogeneity of the occlusion rate of MCA aneurysms found in our meta-analysis.

Since the FDA approval of the PED in 2011, its off-label uses have expanded, including at distal locations. In our series, nearly $60 \%$ of distal aneurysms were treated with the PED. This device was associated with higher occlusion rates compared with the other flow diverters, and the multivariate analysis confirmed that the PED was an independent factor associated with better angiographic results $(\mathrm{OR}=2.6, P=.02)$. Möhlenbruch et $\mathrm{al}^{31}{ }^{31}$ in a recent prospective series, reported a $65 \%$ complete/near-complete occlusion among 12 AcomA aneurysms treated with the FRED Jr, whereas Colby et $\mathrm{al}^{14}$ showed approximately $85 \%$ adequate occlusion after treatment with the PED of 34 AcomA aneurysms. Similarly, occlusion among pericallosal aneurysms ranged from $50 \%$ to $70 \%{ }^{15,31}$ and from $75 \%$ to $100 \%{ }^{1,2,16,22}$ after treatment with the FRED Jr and PED, respectively.

Finally, consistent with the recent literature, ${ }^{38,39}$ the angiographic outcomes were not significantly influenced by using adjunctive coils and multiple stents.

\section{Treatment-Related Complications}

The Aneurysm Study of Pipeline in an Observational Registry ${ }^{35}$ and the International Retrospective Study of Pipeline Embolization Device (IntrePED) ${ }^{40}$ studies reported treatment-related complication rates close to $11 \%$, with $6 \%$ morbidity. Our metaanalysis, focusing on the distal AC aneurysms, showed comparable rates of complications. Most interesting, $10 \%$ of them were ischemic events largely related to perforator injury, acute in-stent thrombosis, or covered side branches. Accordingly, the MCA had the highest rate of complications (18\%), and this location was an independent factor related to adverse events $(\mathrm{OR}=1.8, P=.02)$. This finding is consistent with a recent meta-analysis of FD for MCA aneurysms reporting an overall rate of complications of $21 \%$, with $10 \%$ morbidity. ${ }^{3}$ Overall, almost $3 \%$ of complications were related to the premature discontinuation of the AT. Caroff et $\mathrm{al},{ }^{13}$ in a series of $15 \mathrm{MCA}$ aneurysms treated with $\mathrm{FD}$, reported a transient ischemic attack in the MCA territory after the termination of the dual AT. In a recent series of 17 pericallosal aneurysms, the authors reported 1 complete PED occlusion leading to an irreversible ischemic infarct due to the inadvertent discontinuation of the AT. ${ }^{2}$ These data emphasize the close relationship between antiplatelet function and FD in small and distal vessels.

Binary logistic regression of the individual patient data, consistent with the subgroup analysis, underlined aneurysm size (large aneurysms [ $\geq 10 \mathrm{~mm}$ ] versus small aneurysms $[<10 \mathrm{mml}]$ ) as a factor associated with a higher risk of complications $(\mathrm{OR}=$ $2.2, P=.03)$. Due to their size, intrasaccular thrombosis, neck dimension, and the relationship with neural structures, large/very large aneurysms are often difficult to treat and are associated with high rates of treatment-related morbidity. ${ }^{41}$ Gawlitza et al, ${ }^{18}$ in a series of AcomA and MCA aneurysms treated with FD, reported complications in 5 of the 6 patients with large/giant lesions, while adverse events among small aneurysms were significantly lower (3 of 11 patients). This finding is in accordance with the results of a recent meta-analysis of very large/giant aneurysms showing $29 \%$ complications after FD, without significant differences between FD alone and FD plus coiling. ${ }^{41}$

\section{Outcome of Covered Vessels}

FD stents at the bifurcation points have a potential risk of occlusion of the covered arteries. We found $6 \%$ and $24 \%$ occlusion and narrowing of covered vessels, respectively. There were not significant differences among the studied locations and the devices. Most important, symptoms related to occlusion and arterial nar- 
rowing were both $3 \%$. In the series by Caroff et al, ${ }^{13}$ immediately after treatment, slow flow of the covered M2 caused 6\% and 13\% of transient and permanent deficits, respectively. Pistocchi et $\mathrm{al}^{23}$ reported 5 cases of occlusion and 4 cases of slow flow of the covered A2, among 14 patients with AcomA aneurysm treated with the Silk device, with only 1 patient experiencing a transitory hemiparesis. Saleme et $\mathrm{al}^{4}{ }^{4}$ in a series of 9 AcomA aneurysms treated with the PED, described 2 cases of asymptomatic A2 occlusion during follow-up. Finally, among DACA aneurysms, the rate of flow modification of the covered callosomarginal artery was between $0 \%$ and $30 \%,{ }^{1,2,15,16,22}$ with only 1 case of transient ischemic symptoms. $^{31}$

\section{Strengths and Limitations}

Our study has limitations. Most of the series are small retrospective studies. Although the AT was quite comparable among the studies (On-line Table 2), the influence of the platelet inhibition levels was not evaluated. Fusiform/dissecting aneurysms reported in a few included series can impact the results of our meta-analysis, though we performed a subgroup analysis (dissecting/fusiform versus saccular) and we reasonably excluded this kind of aneurysm from the binary logistic regression. However, publication bias was reasonably excluded, and our review is the largest today on this topic.

\section{CONCLUSIONS}

In general, flow diversion among distal AC aneurysms is effective, leading to adequate aneurysm occlusion in $83 \%$ of cases. Nevertheless, this strategy presents some limitations among MCA and larger lesions, especially related to the higher rate of complications. Compared with the other devices, the PED seems to be associated with a higher occlusion rate.

Disclosures: Paolo Perrini-UNRELATED: Employment: University of Pisa, Comments: Associate Professor at University of Pisa. Davide di Carlo-UNRELATED: Employment: University of Pisa. Alain Bonafe-UNRELATED: Consultancy: Medtronic, Stryker, MicroVention. Vincent Costalat-UNRELATED: Consultancy: Medtronic, Balt, Stryker, Cerenovus; Grants/Grants Pending: Medtronic, Stryker, Cerenovus, Balt, Penumbra*; Payment for Development of Educational Presentations: Stryker, Medtronic, Balt, MicroVention. Pierre-Henri Lefevre-UNRELATED: Payment for Development of Educational Presentations: Medtronic. *Money paid to the institution.

\section{REFERENCES}

1. Lin N, Lanzino G, Lopes DK, et al. Treatment of distal anterior circulation aneurysms with the Pipeline Embolization Device: a US multicenter experience. Neurosurgery 2016;79:14-22 CrossRef Medline

2. Cagnazzo F, Cappucci M, Dargazanli C, et al. Treatment of distal anterior cerebral artery aneurysms with flow-diverter stents: a single-center experience. AJNR Am J Neuroradiol 2018;39:1100-06 CrossRef Medline

3. Cagnazzo F, Mantilla D, Lefevre PH, et al. Treatment of middle cerebral artery aneurysms with flow-diverter stents: a systematic review and meta-analysis. AJNR Am J Neuroradiol 2017;38:2289-94 CrossRef Medline

4. Saleme S, Iosif C, Ponomarjova S, et al. Flow-diverting stents for intracranial bifurcation aneurysm treatment. Neurosurgery 2014; 75:623-31; quiz 631 CrossRef Medline

5. Moher D, Liberati A, Tetzlaff J, et al; PRISMA Group. Preferred Reporting Items for Systematic Reviews and Meta-Analyses: the PRISMA statement. Int J Surg 2010;8:336-41 CrossRef Medline

6. Elsharkawy A, Lehečka M, Niemelä M, et al. A new, more accurate classification of middle cerebral artery aneurysms: computed tomography angiographic study of 1,009 consecutive cases with 1,309 middle cerebral artery aneurysms. Neurosurgery 2013;73:94-102; discussion 102 CrossRef Medline

7. O’Kelly CJ, Krings T, Fiorella D, et al. A novel grading scale for the angiographic assessment of intracranial aneurysms treated using flow diverting stents. Interv Neuroradiol 2010;16:133-37 CrossRef Medline

8. Roy D, Milot G, Raymond J. Endovascular treatment of unruptured aneurysms. Stroke 2001;32:1998-2004 CrossRef Medline

9. Wells G SB, O'Connell D. The Newcastle-Ottawa Scale (NOS) for Assessing the Quality of Nonradomized Studies in MetaAnalyses. Ottawa: Ottawa Hospital Research Institute; 2011. http:// www.ohri.ca/programs/clinical_epidemiology/oxford.asp. Accessed November 5, 2018

10. Riley RD, Lambert PC, Abo-Zaid G. Meta-analysis of individual participant data: rationale, conduct, and reporting. BMJ 2010;340:c221 CrossRef Medline

11. Bhogal P, Martinez R, Gansladt $\mathrm{O}$, et al. Management of unruptured saccular aneurysms of the M1 segment with flow diversion: a single centre experience. Clin Neuroradiol 2018;28:209-16 CrossRef Medline

12. Briganti F, Delehaye L, Leone G, et al. Flow diverter device for the treatment of small middle cerebral artery aneurysms. J Neurointerv Surg 2016;8:287-94 CrossRef Medline

13. Caroff J, Neki H, Mihalea C, et al. Flow-diverter stents for the treatment of saccular middle cerebral artery bifurcation aneurysms. AJNR Am J Neuroradiol 2016;37:279-84 CrossRef Medline

14. Colby GP, Bender MT, Lin LM, et al. Endovascular flow diversion for treatment of anterior communicating artery region cerebral aneurysms: a single-center cohort of $\mathbf{5 0}$ cases. J Neurointerv Surg 2017;9:679-85 CrossRef Medline

15. Dabus G, Grossberg JA, Cawley CM, et al. Treatment of complex anterior cerebral artery aneurysms with Pipeline flow diversion: mid-term results. J Neurointerv Surg 2017;9:147-51 CrossRef Medline

16. De Macedo Rodrigues K, Kühn AL, Tamura T, et al. Pipeline Embolization Device for pericallosal artery aneurysms: a retrospective single center safety and efficacy study. Oper Neurosurg (Hagerstown) 2018;14:351-58 CrossRef

17. De Vries J, Boogaarts J, Van Norden A, et al. New generation of flow diverter (Surpass) for unruptured intracranial aneurysms: a prospective single-center study in 37 patients. Stroke 2013;44:1567-77 CrossRef Medline

18. Gawlitza M, Januel AC, Tall P, et al. Flow diversion treatment of complex bifurcation aneurysms beyond the circle of Willis: a single-center series with special emphasis on covered cortical branches and perforating arteries. J Neurointerv Surg 2016;8:481-87 CrossRef Medline

19. Lin LM, Bender MT, Colby GP, et al. Use of a next-generation multidurometer long guide sheath for triaxial access in flow diversion: experience in 95 consecutive cases. J Neurointerv Surg 2018;10: 137-42 CrossRef Medline

20. Lin LM, Iyer RR, Bender MT, et al. Rescue treatment with Pipeline embolization for postsurgical clipping recurrences of anterior communicating artery region aneurysms. Interv Neurol 2017;6: 135-46 CrossRef Medline

21. Lubicz B, Collignon L, Raphaeli G, et al. Pipeline flow-diverter stent for endovascular treatment of intracranial aneurysms: preliminary experience in 20 patients with 27 aneurysms. World Neurosurg 2011; 76:114-19 CrossRef Medline

22. Nossek E, Zumofen DW, Setton A, et al. Treatment of distal anterior cerebral artery aneurysms with the Pipeline Embolization Device. J Clin Neurosci 2017;35:133-38 CrossRef Medline

23. Pistocchi S, Blanc R, Bartolini B, et al. Flow diverters at and beyond the level of the circle of Willis for the treatment of intracranial aneurysms. Stroke 2012;43:1032-38 CrossRef Medline

24. Rautio R, Rahi M, Katila A, et al. Single-center experience with sixmonth follow-up of FRED Jr flow diverters for intracranial aneu- 
rysms in small arteries. Acta Radiol 2018 Oct 25. [Epub ahead of print] CrossRef Medline

25. Toma AK, Robertson F, Wong K, et al. Early single centre experience of flow diverting stents for the treatment of cerebral aneurysms. $\mathrm{BrJ}$ Neurosurg 2013;27:622-28 CrossRef Medline

26. Topcuoglu OM, Akgul E, Daglioglu E, et al. Flow diversion in middle cerebral artery aneurysms: is it really an all-purpose treatment? World Neurosurg 2016;87:317-27 CrossRef Medline

27. Yavuz K, Geyik S, Saatci I, et al. Endovascular treatment of middle cerebral artery aneurysms with flow modification with the use of the Pipeline embolization device. AJNR Am J Neuroradiol 2014;35: 529-35 CrossRef Medline

28. Zanaty M, Chalouhi N, Tjoumakaris SI, et al. Flow diversion for complex middle cerebral artery aneurysms. Neuroradiology 2014;56: 381-87 CrossRef Medline

29. Bhogal P, AlMatter M, Bäzner H, et al. Flow diversion for the treatment of MCA bifurcation aneurysms: a single centre experience. Front Neurol 2017;8:20 CrossRef Medline Medline

30. Iosif C, Mounayer C, Yavuz K, et al. Middle cerebral artery bifurcation aneurysms treated by extrasaccular flow diverters: midterm angiographic evolution and clinical outcome. AJNR Am J Neuroradiol 2017;38:310-16 CrossRef Medline

31. Möhlenbruch MA, Kizilkilic O, Killer-Oberpfalzer M, et al. Multicenter experience with FRED Jr Flow Re-Direction Endoluminal Device for intracranial aneurysms in small arteries. AJNR Am J Neuroradiol 2017;38:1959-65 CrossRef Medline

32. Pierot L, Spelle L, Berge J, et al. Feasibility, complications, morbidity, and mortality results at 6 months for aneurysm treatment with the Flow Re-Direction Endoluminal Device: report of SAFE study. J Neurointerv Surg 2018;10:765-70 CrossRef Medline

33. Wakhloo AK, Lylyk P, de Vries J, et al; Surpass Study Group. Surpass flow diverter in the treatment of intracranial aneurysms: a prospective multicenter study. AJNR Am J Neuroradiol 2015;36:98-107 CrossRef Medline
34. Brinjikji W, Murad MH, Lanzino G, et al. Endovascular treatment of intracranial aneurysms with flow diverters: a meta-analysis. Stroke 2013;44:442-47 CrossRef Medline

35. Kallmes DF, Brinjikji W, Boccardi E, et al. Aneurysm Study of Pipeline in an Observational Registry (ASPIRe). Interv Neurol 2016;5: 89-99 CrossRef Medline

36. Brinjikji W, Lanzino G, Cloft HJ, et al. Endovascular treatment of middle cerebral artery aneurysms: a systematic review and single-center series. Neurosurgery 2011;68:397-402; discussion 402 CrossRef Medline

37. Alreshidi M, Cote DJ, Dasenbrock $\mathrm{HH}$, et al. Coiling versus microsurgical clipping in the treatment of unruptured middle cerebral artery aneurysms: a meta-analysis. Neurosurgery 2018;83:879-89 CrossRef Medline

38. Sweid A, Atallah E, Herial N, et al. Pipeline-assisted coiling versus Pipeline in flow diversion treatment of intracranial aneurysms. J Clin Neurosci 2018;58:20-24 CrossRef Medline

39. Cagnazzo F, di Carlo DT, Cappucci M, et al. Acutely ruptured intracranial aneurysms treated with flow-diverter stents: a systematic review and meta-analysis. AJNR Am J Neuroradiol 2018;39:1669-75 CrossRef Medline

40. Kallmes DF, Hanel R, Lopes D, et al. International retrospective study of the Pipeline embolization device: a multicenter aneurysm treatment study. AJNR Am J Neuroradiol 2015;36:108-15 CrossRef Medline

41. Cagnazzo F, Mantilla D, Rouchaud A, et al. Endovascular treatment of very large and giant intracranial aneurysms: comparison between reconstructive and deconstructive techniques-a meta-analysis. AJNR Am J Neuroradiol 2018;39:852-58 CrossRef Medline

42. Morais R, Mine B, Bruyère PJ, et al. Endovascular treatment of intracranial aneurysms with the p64 flow diverter stent: mid-term results in 35 patients with 41 intracranial aneurysms. Neuroradiology 2017;59:263-69 CrossRef Medline 